\title{
Measuring the Success of Social Media: Matching Identified Success Factors to Social Media KPIs
}

\author{
Timo Hammerl \\ University of Regensburg \\ timo.hammerl@ur.de
}

\author{
Susanne Leist \\ University of Regensburg \\ susanne.leist@ur.de
}

\author{
Josef-Michael Schwaiger \\ University of Regensburg \\ josef-michael.schwaiger@ur.de
}

\begin{abstract}
With the rise of social platforms such as Facebook, Twitter, Instagram etc., recently, a lot of excitement and optimism around the potential of corporate social media usage have emerged. Social media activities allow companies to reach an attractive mass audience segment, but just as for any other marketing medium, measurement is a critical component of success. Hence, many critical success factors (CSFs) necessary for successful B2C social media efforts have been compiled in literature over the last years. Although these CSFs are numerous, a classification for a purposeful application as well as corresponding key performance indicators (KPIs) for the concrete measurement of CSFs are missing. Therefore, first (1), this research aims at the identification of existing CSFs for social media in enterprises in literature and classifying them by their specific application. Second (2), to allow the definite measurement of CSFs, corresponding KPIs are identified and matched towards them.
\end{abstract}

\section{Introduction}

Over the last decade, social media has become a key component of people's social life as well as the primary communication method worldwide $[1,2]$. The number of people using social media has been increasing tremendously over the last years [3]. However, the use of social media has not only affected the way private persons communicate with one another, but has also led to a shift of customer expectations concerning the communication channels offered by companies [4]. According to [5], by 2011 $72 \%$ of large enterprises had already deployed at least one social media tool. Additionally, already in $2010,40 \%$ of large enterprises also stated that social networking tools as well as blogs were in use for example to efficiently handle customer inquiries (e.g., [6]), widely share marketing material (e.g., [7]) or solve customer complaints quickly (e.g., [8]).

Driven by this dramatic change, companies are heavily engaged these days in integrating upcoming social technologies with their offerings [9].

Using social media channels can result in various benefits for enterprises. Since the focus of this paper lies on B2C applications, the most prominent benefits are twofold. First, social media triggers customer engagement to increase emotional bonds, brand loyalty and to improve the overall business performance. For example, customers may be integrated into so far internal company tasks such as product or service development [10-12]. Second, social media generates "word of mouth", the most persuasive form of advertising and increasing the viral dissemination of information [13, 14].

Even though social media is being used by most enterprises and also well known for being the best modern way of interacting with consumers via the internet $[15,16]$, the know-how of how to use social media as well as of how to extract information from social media to gain concrete benefits in a structured way is fairly low [17].

As user-networks, communities as well as topics and interests within the social media channels are characterized by a steady change, the continuous measurement of proposed social media efforts is absolutely essential. To do so, many researchers as for example [18] provide various critical success factors (CSFs) to determine the success of corporate social media activities. However, diverse CSFs in the literature are often presented in an isolated manner and a consistent classification is missing (e.g., [19, 20]).

Thus, the present research first (1) deals with the identification of CSFs for social media in enterprises and their categorization towards predefined classes resulting in the following research question (RQ):

(1) RQ1: Which CSFs of social media for enterprises (B2C) can be identified in literature and how can they be classified? 
Although, these success factors permit to take aim at specific features of a successful social media offering, the corresponding key performance indicators (KPIs) that measure the performance of a company's social media efforts are mostly missing. Therefore, a combination of CSFs and matching KPIs to measure the performance of social media activities seems promising, leading to the second (2) addressed gap of this research:

(2) RQ2: Which social media KPIs can be matched towards the identified CSFs?

Summing up, the aim of this research is to develop an approach that categorizes existing CSFs for social media at enterprises in the literature by their specific application and combines them with corresponding KPIs. Thus, the approach allows the measurement of the performance of corporate social media usage.

This paper unfolds as follows: in section 2, conceptual basics on social media, CSFs and corresponding KPIs are introduced. Afterwards, the procedure of our research is presented (section 3 ). Section 4 presents and discusses the results of the investigation. The results are then applied on a specific use case and interpreted in section 5. The paper is rounded off with a conclusion, limitations and an outlook on future research.

\section{Conceptual basics}

In literature, the term "social media" is often described as "a group of Internet-based applications that build on the ideological and technological foundations of Web 2.0, and that allow the creation and exchange of User Generated Content (UGC) “ [21]. The field of social media contains various technologies for supporting user or customer engagement respectively, such as online social networks (OSN) (e.g., Facebook), or Wikis amongst others [22].

With their increased adoption by enterprises, the question arises of how to make social media success measurable? Therefore, approaches for the measurement as well as the support of value-creation become more and more significant.

In economic research, an objective approach that is widely used to define success is the degree of the achievement of objectives [23]. This definition appears also in the IS success model of DeLone \& McLean and is described with the indicator "net benefit" [24]. Since social media by definition is not an end in itself but an instrument to achieve certain goals (e.g., [25]), we will use the degree of achievement of these goals as an indicator for its

success. Therefore, we draw upon a second well known concept in economic research from Rockart, who suggests to define CSFs and measure them to reach the defined goals [26].

According to [26], there are three essential components to measure the degree of achievement of goals as shown in figure 1.

\section{GOAL}

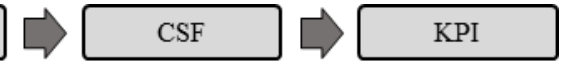

Figure 1. Measurement approach [26]

In order to identify relevant CSFs for the success of social media or the companies' social media efforts, goals need to be defined. According to [27], goals represent the end points that an organization intends to reach at a given point in time. Due to the very individual characteristics of specific company goals, it is necessary to identify CSFs, to facilitate the measurement of relevant metrics and to support the systematization of goals. CSFs are the areas in which good performance is necessary to ensure the achievement of those goals [27].

The respective measurement instruments are KPIs. In the literature, different perceptions regarding KPIs and measures can be found. According to several authors, KPIs are quantifiable measurements and concise indicators designed to measure the achievement of strategic objectives by combining a lot of information [28-30]. Further [31] state that KPIs are often used by an organization to analyze the CSFs of a particular activity in which it is engaged.

\section{Methodology}

To develop an approach, we followed the Design Science (DS) approach [32, 33].

In phase one, problems were identified by unveiling the missing connections between CSFs and corresponding KPIs. Phase two defined the objective of our solution (measurement of social media success based on CSFs and KPIs). To design and develop this solution, we conducted a literature review to identify CSFs as well as KPIs regarding corporate social media usage following the methodology provided by [34]. Afterwards, we manually categorized existing CSFs for social media in enterprises and matched them to corresponding KPIs (phase three). For the demonstration and evaluation (phase four and five) of the developed approach, we applied our solution to a German university and discussed our results in several interviews as well as workshops with the university's responsible social media staff. The publication of the 
results (phase six: communication) is also part of this article.

To proceed with phase three of the DS approach, we conducted a literature review to identify existing CSFs as well as KPIs to fit the proposed model. However, while searching for CSFs, we learned that, to the best of our knowledge, there is no connection between existing CSFs and corresponding KPIs, which is why we conducted a second literature review to identify social media KPIs and matching them afterwards (see section 4.3).

The first literature review regarding CSFs followed the proposed procedure of [35].

First, the review scope was defined in accordance with the research questions (cf. [36], see section 1). As suggested by [35], we drew on an established taxonomy presented by [37].

Second, for the conceptualization of the topic, seminal works that deal with social media (e.g., [3840]) were drawn on to define key terms and to extract key concepts that were later used to define the search terms, databases and the time period for the literature search (see table 1). It turned out to be most promising to search for relevant literature beginning in the year 2003, when social media started to become a global phenomenon and, indeed, first works were found for that year [41] [42]. Since the area of success factors of social media is an interdisciplinary research field, not only IS works were considered, but also works in the fields of finance, marketing, PR, and others.

Third, the initial literature search resulted in a total of 5,049 publications. As described in table 1, this initial search number also resulted from the generic search terms such as "success" and "social media", but in most of them the focus on CSFs was missing. Further, we discovered that older publications did not have any relevance to our approach, even though search terms such as "success factors" were used. This may be attributable to the fact that, in the beginnings, the focus lay more on understanding the functionalities and not on assessing the success of these applications. As a next step, duplicates found in the databases were eliminated. Irrelevant works regarding ERP systems, knowledge systems, maturity models or e-government could also be eliminated. Further, our focus did not lie on the evaluation of Web 2.0 applications (e.g., forums) or virtual worlds, which led to a further reduction of the literature, too. Also, as social media in B2C was in our scope, publications focusing on e.g., enterprise social networks (ESN) or supplier networks were not included. In addition, only peer-reviewed literature was considered, leading to 15 relevant works. On these papers, a backwards and forwards search was conducted that led to an increase to a total number of 17 publications dealing with CSFs in connection with social media. As mentioned, the literature search covered a wide area of research fields resulting in a very diverse set of publications.

The literature analysis as step four is based on the qualitative content analysis according to [43] to answer $R Q 1$. As a first step, the literature was manually searched to identify potential categories (e.g., [18]) (deductive category application).

However, not all identified CSFs could be assigned to the categories as described in [18], hence, self-defined categories were developed by grouping similar CSFs and analyzing what component of social media, in the eyes of the researchers, had the most influence on the success of social media (inductive category development).

Table 1. Overview of search parameters

\begin{tabular}{lc} 
Time period & $2003-2017$ \\
\hline Databases & $\begin{array}{c}\text { Google Scholar; } \\
\text { EBSCOhost; } \\
\text { AISeL; } \\
\text { ScienceDirect }\end{array}$ \\
\hline Search Fields & Full-text, \\
& (except AISeL: Title, \\
& Abstract, Keywords) \\
\hline Search Terms & $\begin{array}{c}\text { Success factors; success; } \\
\text { benefits; enablers } \\
\text { (all combinations) }\end{array}$ \\
& AND \\
& $\begin{array}{l}\text { Social Media; social } \\
\text { networks; OSN; SM }\end{array}$
\end{tabular}

To reduce the subjectivity of the categorization approach [43], all steps (identification of potential categories, assigning CSFs to the categories and selfdefinition of categories) were performed by two researchers individually to reduce subjectivity. In case of disagreement, the article in question was analyzed by a third researcher followed by a discussion until a consensus was reached. This resulted in a total of five categories, three of which were extracted form literature and two self-defined (see section 4.1).

Fifth, a research agenda was compiled by giving an outlook as well as identifying new areas of research in terms of CSFs and KPIs.

As for the second literature review to identify KPIs, Peters et al. [44] could be drawn upon who performed an exhaustive literature review regarding the identification of social media metrics (further called KPIs). Therefore, we chose a representative coverage since [44] already provided the foundations. 
Besides [44], we conducted a forward search with the emphasis on the years 2013 to 2017 and found additional publications to characterize social media metrics further in order to answer $R Q 2$. This literature review led to an analysis of 21 publications.

The matching process of the CSFs to the KPIs was performed by two researchers individually. In case of a disagreement between them, a third researcher would be invited to mediate the discussion until a consensus was reached.

\section{Results and interpretation}

\subsection{Results literature review (CSFs)}

To categorize the CSFs, we identified five clusters in accordance with the approach by [43] as described in section 3 to answer $R Q 1$. These clusters (a combination of already existing classes in the literature (e.g., [18]) and self-defined classes) are User, Content, Management (Mgmt), Determining Factors $(D F)$ and Team, with the latter two resulting from the self-defined classes. Figure 2 illustrates the five identified clusters with the number of identified CSFs.

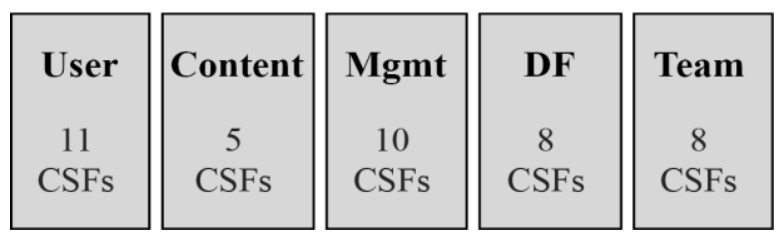

Figure 2. Clusters with number of CSFs.

One finding of the LR is the fact that some authors only define their identified success factors without evidence. Therefore, we divided the identified CSFs into unverified CSFs (marked with an * in table 2) and verified ones. Altogether, 42 CSFs could be identified 12 of which were classified as unverified-CSFs and 30 as verified-CSFs. In the following, an example for each cluster is given.

The cluster User summarizes all CSFs that have a direct impact on the user (e.g., customer, prospect, etc.) of a specific social media network. For this reason, [18] define the interactivity as being an essential CSF. This can be justified with the general characteristic of social media [21] because, without interactivity, there would be no added value to such an application. This CSF also works in favor of engaging with a target group easily, e.g., via responding to users' needs or finding creative ways to address users. In doing so, it is possible to obtain insights into users' preferences enabling to identify more easily users' needs, which eventually leads to a boost in user engagement.

To attract users to certain posts, understanding the specific characteristics of a social media post is an essential part of accomplishing the successful engagement with the users. CSFs concerning these characteristics are summarized in the Content cluster. Providing qualitative content as defined by [40, 45, 46] can support the goal of engaging and attracting users. The adage 'quality over quantity' is applicable here, since providing real value to the users is far more important than posting as much as possible.

Involving the management in the decision process to receive their full support is seen as critical to success [18, 45, 46]. Additionally, having the management's support also makes taking action easier. Due to this reason, CSFs dealing with decision makers are summarized in the cluster Management.

CSFs in the cluster Determining Factors are to be considered by the social media team before implementing a social media strategy in their organization. By acting according to those defined CSFs, the rectification of faults resulting in monetary or human resource costs should be minimized afterwards. [46] state that it is essential to define responsibilities in order to make the whole social media effort and process efficient and to optimize response times for instance. If responsibilities are clear, a social media team knows when and how to take appropriate action.

CSFs adhered to by the social media team are consolidated in the cluster Team. A committed team, as defined by [18], can be relied on, resulting in better posts and more qualitative content, since more efforts are made to bring out the best of social media. The difference between the two clusters Determining Factors and Team is the fact that CSFs in the cluster Team are also applicable, when the implementation of the social media presence is already accomplished.

\subsection{Results literature review (KPIs)}

As described in section 1, we figured out that the CSFs identified by the literature review had not so far been matched to KPIs to make social media success measurable. To close this gap, we elicited widely used KPIs from the literature as a first step to answer $R Q 2$.

As a result of the conducted LR regarding the KPIs, a list containing 99 potential social media KPIs was compiled (e.g., centrality measures, social media key figures, etc.). [44] identified four different domains to which the KPIs were mapped. These domains support the understanding of the specific 
focus of a single KPI and were used to help matching the KPIs to the CSFs as described in section 4.3.

However, the list of 99 KPIs still contained duplicates as well as similar KPIs that could be summerized. For example, the KPIs 'average rating over time' [47], 'average rating' [48], 'rating' [49, 50] and 'difference in ratings' [51] could be summerized to the KPI 'average rating', since these KPI all express fairly the same. After consolidating the KPI list a total of 70 social media metrics remain [50, 52-65].

Due to space restrictions, this full list can not be described here, but is accessable via this web appendix: https://bit.ly/2sYb9Xs.

\subsection{Matching and discussion}

After identifiying the two isolated components, the matching of KPIs to CSFs was conducted manually in accordance with the specific features of those KPIs that allow a potential measurement of success.

The results of the complete matching process are presented in table 2. The first CSF is assigned to the category user and postulates to be unique. Uniqueness in social media requires authenticity and engagement in the way participants of the network share the same values and relate themselves to or identify themselves with the network community, respectively. Because of the qualitative nature of this CSF, a matching KPI should rather capture the effects of authenticity and engagement to the community than authenticity and engagement in itself. Consequently, as corresponding KPIs, vividness, meaning to measure both the number of comments/shares/likes and the response times as well as entertaining content, aiming to capture the share of content that initiates user engagement, are proposed. For the CSF interactivity the interaction rate (e.g., number of comments, shares, likes, ...), the number of postings or ratings as well as the recurring rate (e.g., share of recurring users) are suggested as KPIs to indicate success. Even though a large number of KPIs could be matched, a few CSFs remain for which a useful allocation was not possible, e.g., the qualitative CSF 'cultural consideration' [40] or the CSF 'establishing a project management' [45], the description of which is too vague.

Other CSFs give quite good options to match multiple KPIs. For instance, the CSF 'provide up-todate content' [19, 20, 40, 46] can be measured with KPIs as for example the 'interaction rate [50]', which includes all metrics such as number of likes, number of shares, etc. With up-to-date content it is most likely that such content receives a lot of attention and strikes a chord with the users, which normally results in a high amount of virality. This can lead to an increase of the net-reach meaning that a particular social media site is seen by a lot of users.

The smallest number of KPIs was allocated to the cluster Management due to the fact that only social media KPIs were considered, even though the cluster Management contains CSFs that need a higher number of generic KPIs to successfully measure them - as for example CSFs such as 'human resources for planning and implementation' $[18,19,66]$ or a 'strategy implementation' [45]. These CSFs are applicable to any new project and therefore do not need specific social media KPIs. Hence, in order to achieve better results, it is desirable to also investigate general KPIs in terms of their applicability to the Management CSFs.

However, additional KPIs could easily be developed and allocated to CSFs, such as the cost of warnings (to be allocated to the CSF comply copyright [67]) or the number of slang words (to be allocated to the CSF unprofessionalism $[18,21]$ ), and can be used for further research to extend table 2 .

Multiple allocations of one and the same KPI are presented in table 2. This is due to the fact that the literature describes some generic KPIs, as for example the social media interaction rate, which is applicable to a total of 7 CSFs. This example also suggests that there is not exactly one KPI for each identified CSF.

From the pool of 70 metrics, the interviewed social media experts could match 55 KPIs to corresponding CSFs and answer $R Q 2$. This leads to the assumption that only these 55 KPIs are critical to measuring success, whereas the remaining 15 KPIs need to be reviewed. By glancing at the characteristics of some KPIs, this non-allocation can be explained. For instance, the KPI homophily [53] expresses the positive relationship between the similarity of two nodes in a network and the probability of a tie between them [68]. This coherence between two nodes can be interpreted in many different ways, which is why it was not possible to clearly allocate this KPI to a specific CSF. However, we cannot exclude the fact that, in some other context, this KPI could be useful. Homophily is part of the network structure domain as defined by [53]. Interestingly, this domain also contains most of the afore-mentioned 15 KPIs that could not be matched to CSFs resulting in the assumption that the network structure domain may as well be too generic, which makes a clear allocation of KPIs a challenging task. 
Table 2. CSF and KPI matching

\begin{tabular}{|c|c|c|}
\hline & CSFS & $K P I s$ \\
\hline \multirow{11}{*}{ 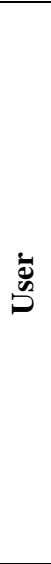 } & Be unique [69] & Vividness [57]; entertaining content [57]; \\
\hline & Identify shared interested [67]* & Informational content [57]; net-reach [50] \\
\hline & Interactivity $[18,70]$ & Interaction rate [50]; \# of postings [55]; \# of ratings [62]; recurring rate [50] \\
\hline & Be interesting [21]* & $\#$ of site visits [50]; recurring rate [50]; \# of subscribers [50]; length of stay [50] \\
\hline & Increase customer happiness $[67]^{*}$ & $\begin{array}{l}\text { \# of positive mentions [50]; customer satisfaction [50]; Net Promoter Score [50]; } \\
\text { Sentiment Index [50]; } \Delta \text { of pos. and neg. chatter [51]; }\end{array}$ \\
\hline & Benefit for the individual [71]* & $\begin{array}{l}\text { \# of pos. product rating [50] ; informational content [57], entertaining content } \\
\text { [57]; vividness [57]; Valence [56] }\end{array}$ \\
\hline & Understanding user needs [19] & $\begin{array}{l}\text { \# of product improvements [50]; \# of product ideas [50]; } \Delta \text { of pos. and neg. } \\
\text { chatter [51] }\end{array}$ \\
\hline & Creative ways to address users [19] & $\begin{array}{l}\text { Aided/unaided recall [50]; \# of attended events [50]; interaction rate [50]; } \\
\text { entertaining content [57] }\end{array}$ \\
\hline & Building trust $[72]^{*}$ & Recommendations [50]; service satisfaction [50]; avg. ratings [47-50]; \\
\hline & Address target group consistent [40] & Reach within target group [50]; net-reach [50]; \\
\hline & Social connection $[70,73]$ & Interaction rate [50]; \# of subscribers [50]; \\
\hline \multirow{8}{*}{ 瓷 } & $\begin{array}{l}\text { (Web) Application knowledge }[18,21, \\
69,74]\end{array}$ & Reduction of workshop costs [50]; degree of knowledgeability [50] \\
\hline & User-friendliness $[40,70,71]$ & Time saving in regards of communication [50] \\
\hline & Comply copyright $[67]^{*}$ & - \\
\hline & Personalization $[40]$ & recurring rate [50]; \# of visits [50] \\
\hline & Set up Guidelines / Netiquette $[40,45]$ & Sentiment Index [50]; valance of information [56] \\
\hline & Privacy protection $[40,67]$ & - \\
\hline & Social media is personal [20] & Interaction rate [50]; response rate $[50]$ \\
\hline & Define responsibilities [46] & Reaction speed [50]; time and staff expenses per service request [50] \\
\hline \multirow{8}{*}{$\stackrel{\Xi}{\overparen{E}}$} & Be active $[21]^{*}$ & $\begin{array}{l}\text { Interaction rate [50]; frequency of contacts [50]; reaction speed [50]; net-reach } \\
{[50] ; \# \text { of postings [55]; }}\end{array}$ \\
\hline & Collaboration $[70,74]$ & $\begin{array}{l}\text { \# of product improvements [50]; \# of product ideas [50]; \# of requests answered } \\
\text { by the community [50], bidirectional link intensity [53] }\end{array}$ \\
\hline & Engage in conversations $[67,74]^{*}$ & Interaction rate [50], reaction speed [50] \\
\hline & Committed team $[18,70]$ & Churn rate [50]; employee satisfaction [50] \\
\hline & Identify and determine KPIs [69] & - \\
\hline & Cultural consideration $[40]$ & - \\
\hline & Reaction speed $[66,67]^{*}$ & Reduction of response time [50] \\
\hline & Conduct workshops $[45,46,70]$ & $\begin{array}{l}\text { Employee satisfaction [50]; \# of operating errors [50]; churn rate [50]; service } \\
\text { satisfaction [50] }\end{array}$ \\
\hline \multirow{5}{*}{ نٍ } & Be honest $[18,21]$ & \# of recommendations [50], avg. ratings [47-50] \\
\hline & $\begin{array}{l}\text { Provide qualitative content }[40,45 \\
46,70]\end{array}$ & $\begin{array}{l}\text { rate of growth [50]; retention period [50], conversion intensity [50]; vividness } \\
\text { [57]; informational/entertaining content [57] }\end{array}$ \\
\hline & Constant posts [18] & avg. net-reach [50]; \# of postings [55] \\
\hline & Unprofessionalism $[18,21]$ & - \\
\hline & $\begin{array}{l}\text { Provide up-to-date content }[19,20,40, \\
46,70]\end{array}$ & $\begin{array}{l}\text { avg. net-reach [50], interaction rate [50], rate of growth [50]; retention period } \\
\text { [50], conversion intensity [50], share of buzz [50]; interactivity [57]; } \\
\text { informational/entertaining content [57] }\end{array}$ \\
\hline \multirow{10}{*}{ 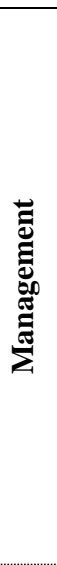 } & Building a Reputation [40] & $\begin{array}{l}\text { \# positive mentions [50]; brand awareness/popularity [50]; recommendations } \\
\text { [50]; sentiment index [50]; contentment [50]; \# of job applications [50]; net } \\
\text { promoter Score [50]; }\end{array}$ \\
\hline & High level of social presence [67]* & Interaction rate [50]; interactivity [57] \\
\hline & Providing no alternatives $[70,71]$ & - \\
\hline & Cheap advertisement [20] & costs for social media ads vs. costs for traditional ads [50]; net-reach [50] \\
\hline & Management Support $[18,45,46]$ & $\begin{array}{l}\text { employee satisfaction [50], spending for further trainings [50]; labor turnover- } \\
\text { rate [50]; employee-rating [50] }\end{array}$ \\
\hline & $\begin{array}{l}\text { Annoying but necessary } \\
\text { advertisement }[20]\end{array}$ & \# ad conversions [50]; avg. ratings [47-50] \\
\hline & $\begin{array}{l}\text { Human Resources for planning and } \\
\text { implementation }[18,19,66]\end{array}$ & - \\
\hline & Establish project management $[45]^{*}$ & - \\
\hline & Social responsibility [20] & - \\
\hline & Strategy implementation [45]* & - \\
\hline
\end{tabular}


Hence, as our research agenda, it needs to be investigated more precisely what KPIs of the network structure domain contribute for the success of social media. Also, the network structure domain in general seems promising for further research regarding social media success. This domain contains a lot of KPIs that describe features of social media as defined by [21]. As for example, centrality measures give an insight into how influential persons are in a network [53] therefore contributing to the exchange of UGC. Furthermore, it needs to be investigated how social media success can be defined in greater detail, since the identified $42 \mathrm{CSF}$ and $70 \mathrm{KPIs}$ provide a capital basis for explaining social media success. Additionally, more generic KPIs (e.g., for the cluster Management) need to be taken into consideration for further research.

\section{Demonstration}

The demonstration of our approach takes place in a German university having just recently started their social media activities. We aimed at demonstrating the usefulness of our approach for both novices as well as experts in the field of social media. Since the university's social media team consists of these two groups, this use case was suitable. Also, the target group of the university is fairly young (prospect students), which makes it even more promising, since young users are believed to be more affine to social media and therefore more active. Furthermore, as [75] compares universities with service companies, we were able to further prove the applicability of our approach in the $\mathrm{B} 2 \mathrm{C}$ area. We accompanied this social media project and observed the application of our approach from March to May 2018.

As a first step, the university's social media team defined the specific social media goals that were seen as indicators for the success of the project. In so doing, the team specified the purpose of the social media presence (attraction of students) in compliance with the main goals of the university and derived the following three social media goals: building a reputation (1), developing a community for better (knowledge) exchange (2) as well as developing a social media governance (3).

The second step involved the selection of relevant CSFs and KPIs. In accordance with Rockart [27], not all possible CSFs were selected, but only the most promising indicators of the degree of achievement of the goals and correspondingly of the success. In three discussion rounds with the university's social media staff, a consensus on the most relevant CSFs was reached, which are 'provide up-to-date content' [19,
20, 40, 46], 'reaction speed' $[66,67]$ and 'interactivity' [18]. Thus, afterwards, the relevant KPIs to measure the achievement of these CSFs could easily be identified with the help of table 2 .

Providing up-to-date content $[19,20,40,46]$ helps to attract more persons who use the social media site as an information source, possibly triggering discussions on a specific topic, resulting in a higher interaction rate [50]. By engaging in these discussions, the university's social media staff can support the users by answering their requests, which can eventually lead to improving the university's reputation (1) by publicly addressing the concerns of its fans (e.g., students). The university's reaction speed to requests is also critical to success [66, 67]. As German universities, in general, have the reputation of taking their time to provide the desired information, a reduced response time [50] can help to reach the defined goals. Interactivity, for instance, can be measured by the recurring rate [50], the number of postings [55] as well as by the number of ratings [62] and the social media interaction rate [50]. Since interactivity [18] is an essential part of the definition of social media [21] (see section 2), it should also be a mandatory CSF.

To investigate the usefulness of our approach, we set up a workshop to discuss its application with the social media team. Particular emphasis was laid on both the relevance and the comprehensibility of the approach: The social media team considered the approach as appropriate for being used in social media projects, especially emphasizing its effective support in selecting relevant CSFs and KPIs with the help of table 2. The team substantiated their approval by reporting an impressive experience they had made: to raise interaction via comments (e.g., trading requests), likes and shares, a post dealing with the then upcoming soccer world cup was created offering the users to collect and exchange popular soccer player cards. Much to the team's surprise, barely any interaction was achieved. Another post that was only considered as an informational post without the intention of creating or even raising interaction achieved a huge number of likes and comments, underlining its popularity. This post was used for the creation of a campaign called 'university faces', where students, employees and professors were interviewed to convey a more "private" picture of themselves to the social media users.

It turned out, however, that identifying relevant CSFs is challenging so that extending the list with corresponding social media goals would be of great help. Specifically, the way of describing the goals is crucial as this description determines their applicability in this context. The achievement of 
success regarding abstract or generic goals can be measured by too many CSFs. A thorough trade-off between goals, as abstract as possible and as specific as necessary, will be of great importance for the further development of our approach. Although the university's social media project is still in an early phase, the social media team has already been able to identify and stress the necessity of continuously using the approach and evolving and adapting CSFs as well as KPIs, since success in social media depends on different factors such as the changing background of user preferences or new technical solutions.

A tool to automatically analyze the degree of goal achievement by measuring the degree of fulfilling defined CSFs would be helpful. To integrate social media analytics into such a tool in order to access social media data, recommendations regarding alternative CSFs can be given in case of being behind schedule with the achievement of goals.

\section{Conclusion}

This research paper addresses the identified gap of a nonexistent allocation of KPIs to corresponding CSFs to make the success of social media measurable by using the basic idea of [26]. To close this gap, we developed an approach by applying design science according to [32, 33]. First, we conducted two literature reviews in order to identify relevant social media CSFs as well as KPIs and matched them.

To demonstrate its applicability, the approach was applied to a social media project at a university in Germany, followed by a discussion of its usability with the responsible social media team.

Our research contributes to both theory and practice. As a contribution to theory, we developed a comprehensive overview of all CSFs and KPIs regarding the use of social media and organized them in five clusters. The resulting list can be seen as an important step for measuring social media success. By applying our approach to a social media project at a German university, we could prove its appropriateness in practical settings. The results of the application were discussed in a workshop with the social media team, as a first step towards the evaluation of our approach, which was considered meaningful as were the selected CSFs and their corresponding KPIs.

However, our research is not without limitations. Although we conducted a comprehensive literature review, some CSFs or KPIs still might have been left out in the search process. Also, an empirical study to evaluate the CSFs needs to be conducted. In addition to the pilot project, further validations of the approach would provide deeper insight into the general applicability of our approach for further refinements.

The findings presented in our paper also point to areas of further research, such as the extension of the table with social media goals and the need for a success measurement tool that enables the monitoring of social media success regarding CSFs and KPIs. Furthermore, an investigation of the network structure domain [53] together with its contribution to success seems promising. Additionally, extending this study by introducing data mining analysis tools to obtain deeper insights into the frequency of the used KPIs and CSFs as well as their characteristics in the papers.

\section{References}

[1] Dickey, I.J., and Lewis, W.F., "The evolution (revolution) of social media and social networking as a necessary topic in the marketing curriculum: a case for integrating social media into marketing classes", Advances in Marketing: Embracing Challenges and Change-A Global Perspective, Publisher, 2010

[2] PWC, 'Social Media Deutschland:" The winner takes it all"-Studie unter 1.000 Nutzern zu ihrer Einstellung zu sozialen Medien', Pwc, 2012, pp. 1-72

[3] Chaffey, D., 'Global social media research summary 2016', 2016,

[4] Berthon, P.R., Pitt, L.F., Plangger, K., and Shapiro, D., "Marketing meets Web 2.0, social media, and creative consumers: Implications for international marketing strategy", Business horizons, Publisher, 2012 55, (3), pp. 261-271.

[5] Bughin, J., Byers, A.H., and Chui, M., "How social technologies are extending the organization", McKinsey Quarterly, Publisher, 2011 20, (11), pp. 1-10.

[6] Culnan, M.J., McHugh, P.J., and Zubillaga, J.I., "How large US companies can use Twitter and other social media to gain business value", MIS Quarterly Executive, Publisher, 2010 9, (4), pp. 243-259.

[7] Gallaugher, J., and Ransbotham, S., "Social media and customer dialog management at Starbucks", MIS Quarterly Executive, Publisher, 2010 9, (4), pp. 197-212.

[8] Pinto, M.B., and Mansfield, P., "Facebook as a complaint mechanism: An investigation of millennials", Journal of Behavioral Studies in Business, Publisher, 2012 5, pp. 1-12.

[9] Trainor, K.J., Andzulis, J.M., Rapp, A., and Agnihotri, R., "Social media technology usage and customer relationship performance: A capabilities-based examination of social CRM", Journal of Business Research, Publisher, 2014 67, (6), pp. 1201-1208.

[10] Mitic, M., and Kapoulas, A., "Understanding the role of social media in bank marketing", Marketing Intelligence \& Planning, Publisher, 2012 30, (7), pp. 668-686. 
[11] Pagani, M., and Mirabello, A., "The influence of personal and social-interactive engagement in social TV web sites", International Journal of Electronic Commerce, Publisher, 2011 16, (2), pp. 41-68.

[12] Sashi, C., "Customer engagement, buyer-seller relationships, and social media", Management decision, Publisher, 2012 50, (2), pp. 253-272.

[13] Chan, Y.Y., and Ngai, E.W., "Conceptualising electronic word of mouth activity: An input-process-output perspective", Marketing Intelligence \& Planning, Publisher, 2011 29, (5), pp. 488-516.

[14] Jalilvand, M.R., and Samiei, N., "The impact of electronic word of mouth on a tourism destination choice: Testing the theory of planned behavior (TPB)", Internet Research: Electronic Networking Applications and Policy, Publisher, 2012 22, (5), pp. 591-612.

[15] Hackworth, B.A., and Kunz, M.B., "Health care and social media: bulding relationships via social networks", Academy of Health Care Management Journal, Publisher, 2011 7, (2), pp. 1-14.

[16] Selina, D., and Milz, T., "Social media will be a driving force for relationship development", Credit Union Journal, Publisher, 2009 13, (32), pp. 16.

[17] Dong-Hun, L., "Korean consumer \& society: growing popularity of social media and business strategy", SERI Quarterly, Publisher, 2010 3, (4), pp. 112.

[18] Stocker, A., and Tochtermann, K., Wissenstransfer mit Wikis und Weblogs: Fallstudien zum erfolgreichen Einsatz von Web 2.0 in Unternehmen, Springer-Verlag, 2011).

[19] Bermúdez-Tamayo, C., Alba-Ruiz, R., JiménezPernett, J., García Gutiérrez, J.-F., Traver-Salcedo, V., and Yubraham-Sánchez, D., "Use of social media by Spanish hospitals: perceptions, difficulties, and success factors", Telemedicine and e-Health, Publisher, 2013 19, (2), pp. 137-145.

[20] Campbell, S.R., Anitsal, I., and Anitsal, M.M., " Social Media's Key Success Factors: An Analysis Of Customer Reactions", Business Studies Journal, Publisher, 2013 5, (1), pp. 1-112.

[21] Kaplan, A.M., and Haenlein, M., "Users of the world, unite! The challenges and opportunities of Social Media", Business horizons, Publisher, 2010 53, (1), pp. 59-68.

[22] Turban, E., Sharda, R., and Delen, D., Decision support and business intelligence systems, Pearson Education India, 2011).

[23] Fritz, W., Marketing-Management und Unternehmenserfolg: Grundlagen und Ergebnisse einer empirischen Untersuchung, Schäffer-Poeschel, 1995).

[24] Delone, W.H., and McLean, E.R., "The DeLone and McLean model of information systems success: a ten-year update", Journal of management information systems, Publisher, 2003 19, (4), pp. 9-30.

[25] Kreutzer, R.T., and Hinz, J., 'Möglichkeiten und Grenzen von Social Media Marketing, Working Papers of the Institute of Management Berlin at the Berlin School of Economics and Law (HWR Berlin), 2010, pp. 1-44.

[26] Bullen, C.V., and Rockart, J.F., "A primer on critical success factors", Publisher, 1981, pp. 1-64.

[27] Rockart, J.F., "Chief executives define their own data needs", Harvard business review, Publisher, 1979 57, (2), pp. 81-93.
[28] Davenport, T.H., and Beck, J.C., "Getting the attention you need", Harvard Business Review, Publisher, 2000 78, (5), pp. 118-126, 200.

[29] Pavlou, P., Housel, T., Rodgers, W., and Jansen, E., "Measuring the return on information technology: A knowledge-based approach for revenue allocation at the process and firm level", Publisher, 2005

[30] Alberghini, E., Cricelli, L., and Grimaldi, M., "KM versus enterprise 2.0: a framework to tame the clash", International Journal of Information Technology and Management, Publisher, 2013 12, (3-4), pp. 320-336.

[31] Alberghini, E., Cricelli, L., and Grimaldi, M., "A methodology to manage and monitor social media inside a company: a case study", Journal of Knowledge Management, Publisher, 2014 18, (2), pp. 255-277.

[32] Hevner, A.R., March, S.T., Park, J., and Ram, S., "Design science in information systems research", MIS quarterly, Publisher, 2004 28, (1), pp. 75-105.

[33] Peffers, K., Tuunanen, T., Rothenberger, M.A., and Chatterjee, S., "A design science research methodology for information systems research", Journal of management information systems, Publisher, 2007 24, (3), pp. 45-77.

[34] Webster, J., and Watson, R.T., "Analyzing the past to prepare for the future: writing a literature review", MIS Q., Publisher, 2002 26, (2), pp. xiii-xxiii.

[35] Vom Brocke, J., Simons, A., Niehaves, B., Riemer, K., Plattfaut, R., and Cleven, A., 'Reconstructing the giant: On the importance of rigour in documenting the literature search process', 2009, pp. 2206-2217.

[36] Cooper, H.M., "Organizing knowledge syntheses: A taxonomy of literature reviews", Knowledge, Technology \& Policy, Publisher, 1988 1, (1), pp. 104-126.

[37] Cooper, H.M., "Organizing knowledge syntheses: A taxonomy of literature reviews", Knowledge in Society, Publisher, 1988 1, (1), pp. 104-126.

[38] Rossmann, A., "Auf der Suche nach dem Return on Social Media", Institut für Marketing - Universität St. Gallen, Publisher, 2013, pp. 1 - 49.

[39] Constantinides, E., and Stagno, M.C.Z., "Higher Education Marketing: A Study on the Impact of Social Media on", Marketing Strategies for Higher Education Institutions: Technological Considerations and Practices: Technological Considerations and Practices, Publisher, 2013 128, pp. 41-58.

[40] Mohammadian, M., and Mohammadreza, M., "Identify the success factors of social media (marketing perspective)", International Business and Management, Publisher, 2012 4, (2), pp. 58-66.

[41] Heidemann, J., Klier, M., and Probst, F., "Online social networks: A survey of a global phenomenon", Computer Networks, Publisher, 2012 56, (18), pp. 38663878 .

[42] Richter, D., Riemer, K., and vom Brocke, J., "Internet social networking", Business \& Information Systems Engineering, Publisher, 2011 3, (2), pp. 89-101.

[43] Mayring, P., "Qualitative content analysis: theoretical foundation, basic procedures and software solution", Publisher, 2014 
[44] Peters, K., Chen, Y., Kaplan, A.M., Ognibeni, B., and Pauwels, K., "Social media metrics-A framework and guidelines for managing social media", Journal of interactive marketing, Publisher, 2013 27, (4), pp. 281-298. [45] Granitzer, G., and Tochtermann, K., 'Web 2.0 in Unternehmen-Eine Fallstudien-Analyse', Citeseer, 2009, pp. 68-76.

[46] Zeiller, M., and Schauer, B., 'Adoption, motivation and success factors of social media for team collaboration in SMEs', ACM, 2011, pp. 1-8.

[47] Godes, D., and Silva, J.C., "Sequential and temporal dynamics of online opinion", Marketing Science, Publisher, 2012 31, (3), pp. 448-473.

[48] Sun, M., "How does the variance of product ratings matter?", Management Science, Publisher, 2012 58, (4), pp. 696-707.

[49] Sridhar, S., and Srinivasan, R., "Social influence effects in online product ratings", Journal of Marketing, Publisher, 2012 76, (5), pp. 70-88.

[50] Wirtschaft, B.D., "Erfolgsmessung in Social Media", Publisher, 2016

[51] Tirunillai, S., and Tellis, G.J., "Does chatter really matter? Dynamics of user-generated content and stock performance", Marketing Science, Publisher, 2012 31, (2), pp. 198-215.

[52] Adjei, M.T., Noble, S.M., and Noble, C.H., "The influence of $\mathrm{C} 2 \mathrm{C}$ communications in online brand communities on customer purchase behavior", Journal of the Academy of Marketing Science, Publisher, 2010 38, (5), pp. 634-653.

[53] Ansari, A., Koenigsberg, O., and Stahl, F., "Modeling multiple relationships in social networks", Journal of Marketing Research, Publisher, 2011 48, (4), pp. 713-728.

[54] Berger, J., Sorensen, A.T., and Rasmussen, S.J., "Positive effects of negative publicity: When negative reviews increase sales", Marketing Science, Publisher, 2010 29, (5), pp. 815-827.

[55] Chen, Y., Fay, S., and Wang, Q., "The role of marketing in social media: How online consumer reviews evolve", Journal of Interactive Marketing, Publisher, 2011 25, (2), pp. 85-94.

[56] Chintagunta, P.K., Gopinath, S., and Venkataraman, S., "The effects of online user reviews on movie box office performance: Accounting for sequential rollout and aggregation across local markets", Marketing Science, Publisher, 2010 29, (5), pp. 944-957.

[57] De Vries, L., Gensler, S., and Leeflang, P.S., "Popularity of brand posts on brand fan pages: An investigation of the effects of social media marketing", Journal of interactive marketing, Publisher, 2012 26, (2), pp. 83-91.

[58] Katona, Z., Zubcsek, P.P., and Sarvary, M., "Network effects and personal influences: The diffusion of an online social network", Journal of marketing research, Publisher, 2011 48, (3), pp. 425-443.

[59] Liu-Thompkins, Y., and Rogerson, M., "Rising to stardom: An empirical investigation of the diffusion of user-generated content", Journal of Interactive Marketing, Publisher, 2012 26, (2), pp. 71-82.

[60] Mallapragada, G., Grewal, R., and Lilien, G., "Usergenerated open source products: Founder's social capital and time to product release", Marketing Science, Publisher, 2012 31, (3), pp. 474-492.

[61] Moe, W.W., and Schweidel, D.A., "Online product opinions: Incidence, evaluation, and evolution", Marketing Science, Publisher, 2012 31, (3), pp. 372-386.

[62] Moe, W.W., and Trusov, M., "The value of social dynamics in online product ratings forums", Journal of Marketing Research, Publisher, 2011 48, (3), pp. 444-456.

[63] Ransbotham, S., Kane, G.C., and Lurie, N.H., "Network characteristics and the value of collaborative user-generated content", Marketing Science, Publisher, 2012 31, (3), pp. 387-405.

[64] Stephen, A.T., and Toubia, O., "Deriving value from social commerce networks", Journal of marketing research, Publisher, 2010 47, (2), pp. 215-228.

[65] Trusov, M., Bodapati, A.V., and Bucklin, R.E., "Determining influential users in internet social networks", Journal of Marketing Research, Publisher, 2010 47, (4), pp. 643-658.

[66] Mauroner, O., and Fauck, D., "Social Media in Science Marketing-Framework, Instruments, and Strategies. Cases from German Research Institutes", Open Journal of Business and Management, Publisher, 2014 2, (03), pp. 250.

[67] Kietzmann, J.H., Hermkens, K., McCarthy, I.P., and Silvestre, B.S., "Social media? Get serious! Understanding the functional building blocks of social media", Business horizons, Publisher, 2011 54, (3), pp. 241-251.

[68] McPherson, M., Smith-Lovin, L., and Cook, J.M., "Birds of a feather: Homophily in social networks", Annual review of sociology, Publisher, 2001 27, (1), pp. 415-444.

[69] Hanna, R., Rohm, A., and Crittenden, V.L., "We're all connected: The power of the social media ecosystem", Business Horizons, Publisher, 2011 54, (3), pp. 265-273.

[70] Lee, C.S., Watson-Manheim, M.B., Chudoba, K.M., and Lee, C.H., 'Use of Social Media in the Workplace', 2013, pp. 1-16.

[71] Koch, M., "Enterprise 2.0... Social Software in Unternehmen", White Paper, Universität der Bundeswehr München, Publisher, 2008, pp. 1-4.

[72] Ainin, S., Parveen, F., Moghavvemi, S., Jaafar, N.I., and Mohd Shuib, N.L., "Factors influencing the use of social media by SMEs and its performance outcomes", Industrial Management \& Data Systems, Publisher, 2015 115, (3), pp. 570-588.

[73] Larson, K., and Watson, R., "The value of social media: toward measuring social media strategies", Publisher, 2011

[74] Blankenship, M., "How social media can and should impact higher education", The Education Digest, Publisher, $201176,(7)$, pp. 39 - 42.

[75] Shank, M., Walker, M., and Hayes, T., 'University service expectations: a marketing orientation applied to higher education', AMA Chicago, IL, 1993, pp. 100-111. 